\title{
Assessment of Knowledge, Attitudes, and Propensity towards HPV Vaccine of Young Adult Students in Italy
}

\author{
Cecilia Trucchi $1,2, *\left(\mathbb{0}\right.$, Daniela Amicizia $1,2,3 \mathbb{0}$, Silvio Tafuri ${ }^{4}$, Laura Sticchi ${ }^{2,3}$, \\ Paolo Durando ${ }^{2,3}$, Claudio Costantino ${ }^{5}$ (D) Federica Varlese ${ }^{1}$, Bruno Di Silverio ${ }^{1,2}$, \\ Anna Maria Bagnasco ${ }^{3}$, Filippo Ansaldi ${ }^{1,2,3}$ and Giancarlo Icardi ${ }^{2,3}$ (D) \\ 1 A.Li.Sa. Liguria Health Authority, 16121 Genoa, Italy; daniela.amicizia@unige.it (D.A.); \\ federica.varlese@regione.liguria.it (F.V.); bruno.disilverio@regione.liguria.it (B.D.S.); \\ filippo.ansaldi@unige.it (F.A.) \\ 2 IRCCS San Martino Hospital, 16132 Genoa, Italy; sticchi@unige.it (L.S.); paolo.durando@unige.it (P.D.); \\ icardi@unige.it (G.I.) \\ 3 Department of Health Sciences, University of Genoa, 16132 Genoa, Italy; annamaria.bagnasco@unige.it \\ 4 Policlinico General Hospital, 70124 Bari, Italy; silvio.tafuri@uniba.it \\ 5 Department of Health Promotion Sciences, Maternal and Infant Care, Internal Medicine and Excellence \\ Specialties (PROMISE), University of Palermo, 90127 Palermo, Italy; claudio.costantino01@unipa.it \\ * Correspondence: cecilia.trucchi@regione.liguria.it; Tel.: +39-010-548-8218
}

Received: 31 December 2019; Accepted: 6 February 2020; Published: 7 February 2020

\begin{abstract}
Background: Human Papillomavirus (HPV) is a common sexually transmitted infection (STI), representing the main cause of genital warts and cervical cancer. This cross-sectional study evaluated knowledge and attitudes about HPV infection, related diseases, and prevention and propensity towards HPV vaccine among undergraduate students. Methods: An online and written survey about HPV and its prevention, targeted to young adults of both genders, was addressed to students attending health sciences and other schools at Universities of Genoa and Bari. Results: The overall median knowledge and attitude scores were 56.3\% (25-75 $p=40-68.8 \%)$ and four out of five (25-75 $p=4-5)$, respectively. In the multivariate analysis, attending a health sciences university, using social networks $\leq 2 \mathrm{~h}$ a day, a history of STI, having heard about HPV and HPV vaccine previously resulted as predictors of higher knowledge scores. Having heard about HPV previously also predicted a high attitude score, together with a perceived economic status as good. Having Italian and healthcare worker parents, being employed, and following a specific diet, instead, predicted lower attitude score. Conclusions: Poor knowledge and good attitudes were found among undergraduates about HPV. In order to increase HPV vaccine compliance and the counselling skills of future healthcare workers, the improvement of training on HPV is needed.
\end{abstract}

Keywords: HPV; knowledge; practice; attitude; young adults; vaccination; student; prevention; sexually transmitted infection

\section{Introduction}

Human papillomavirus (HPV) infection is recognized as the most common STI worldwide [1,2]. HPV infection is acquired soon after sexual debut, it is transient and cleared at an early age [3]. If persistent, it can lead to a wide range of benign lesions and cancers, affecting the ano-genital and the oropharyngeal tract in both sexes [4]. Of note, official epidemiological estimates report 570,000 cases and 311,000 deaths due to cervical cancer in 2018 worldwide, placing the disease as the fourth most frequently diagnosed cancer and the fourth leading cause of cancer death in women [5]. The risk factors involved in the evolution of HPV-related diseases are the efficiency of the host's immune response and 
the characteristics of the virus, including the genotype, the presence of multiple HPV infections, the viral load and integration in the host genome [6]. Co-factors related to the development of ano-genital cancers are alcohol, smoking, and the presence of co-infections with other pathogens [7,8].

Data acquired in recent years confirm that HPV vaccines and screening are the most effective prevention tools [9]; in particular, solid evidence is accumulating about vaccine effectiveness, long-lasting protection, and economic benefits in the avoiding cases [10,11]. Indeed vaccination programs have been implemented in 74 countries all over the world ( 33 countries in the WHO European Region) targeting girls and 11 targeted to boys, achieving successful results [12]. In Italy, the HPV vaccine started in 2007, with a strategy of active call and free-of-charge vaccines targeting girls aged 11-12 years [13]. Then the vaccination program was extended to males aged 11-12 years and at-risk subjects (men who engage in same-sex sexual behaviors) $[14,15]$ following the latest evidence about the cost-effectiveness of HPV vaccination in other targets [16]. Furthermore, women aged 25 years, at the moment of cervical cancer screening can benefit from the HPV vaccine, as recommended by the National Vaccine Plan 2017-2019.

Despite this prevention opportunity, the coverage rate is still suboptimal in Italy, as in other countries, due to HPV vaccination uptake barriers, such as inadequate knowledge of HPV infection and related diseases, vaccination safety concerns, organizational aspects of HPV vaccine campaigns, and difficulties in vaccine schedule completion for subjects and providers [17]. In order to investigate the level of knowledge of HPV infection and vaccination, as well as the attitudes towards recommending the anti-HPV vaccine, an ad hoc knowledge and attitudes questionnaire was developed and administered to Italian young adult students.

\section{Materials and Methods}

\subsection{Study Design and Participants}

A cross-sectional multicenter survey about HPV and its prevention, targeted to young adults of both genders, was carried out from May 2017 to December 2018. The study population included females who retain the right to free-charge vaccination, males who can benefit from the vaccine in co-payment regimens, and subjects at risk, like those who are HIV-positive and men who have sex with men. Recruitment of the study participants took place at the University of Genoa (Liguria region, Northwest Italy), University of Bari (Apulia region, Southern Italy), and the San Martino Hospital in Genoa. In particular, subjects were recruited among students attending healthcare profession schools (i.e., nurses and healthcare assistants) who are required to periodically undergo a medical examination at occupational health surveillance outpatient clinics and who are attending academic schools including public health and prevention subjects in the first and second academic years. The study staff enrolled the students at the outpatient clinic and on the occasion of academic lessons. The sample size was calculated considering the number of subjects belonging to the target study population, the at-risk subjects, and healthcare personnel, the available evidence about the HPV vaccine acceptability fixing the confidence interval at $95 \%$, a margin of error $(+/-)$ of $2.5 \%$, and adding a quota of $5 \%$, in consideration of the possible drop-outs and missed answers.

\subsection{Data Collection and Questionnaire}

Ad hoc anonymous questionnaires addressed to young adults were developed. They were self-administered using the Google Drive platform that automatically populates and saves digital responses into a secure Microsoft Excel database protecting participant confidentiality throughout the surveying process. A consent page reporting the study aims and objectives, the participant's right to the refusal or the possibility to terminate the participation in the study at any time and without disadvantages was created.

Participants could also fill two written informed consent and questionnaires characterized by the same structure of those administered online. The first questionnaire was set in two sections: the 
first one investigated the country of parent's birth, level of parent's education, parent's occupation, and, for the participant, demographics, level of education, occupation, economic status, professed religion, healthy behavior, such as following a specific nutritional regimen (diet) and sport practice, sexual behaviors and orientation, use of the Internet and social networks, the sources used for seeking information on sexually transmitted diseases (STDs), including HPV, and remembering about vaccines received during childhood. The first section also included a 10-point Likert scale ranking the interest to receive an HPV vaccine. The second section included 13 questions on the knowledge on HPV infection, related diseases, and vaccine. The second questionnaire assessed their attitude using nine statements with a five-point Likert scale for each one (5 points- Strongly Agree, 4 point-Agree, 3 points-Neutral, 2 points-Disagree, 1 points-Strongly Disagree). It also included a 10-point Likert scale on how much the participant was interested to receive HPV vaccine after reading some information on HPV infection, related diseases, and vaccine included at the beginning of the second questionnaire (self-learning). Based on the participants' responses, the knowledge, attitude, and intention scores were calculated. The 'knowledge' score summarizes the percentage of correct answers the participants gave among the knowledge questions. For each knowledge statement, one point was given for a correct answer (true or false) and zero points if they selected a wrong answer or "Do not know". The total points were added for every participant and a percentage was calculated (number of correct answers/number of knowledge statements $\times 100$ ). The higher the knowledge score, the more knowledgeable the participant is regarding HPV infection, its related diseases, and prevention. The attitude score was obtained by calculating the average of the participants' responses to the statements on a five-point Likert scale. The median of the total points was calculated for every participant obtaining an attitude score ranging from 1.0 to 5.0. The closer the attitude score to 5, the more positive the participant's attitudes. The "intention" score reflects the propensity toward the HPV vaccine. The "intention" score was estimated both at the beginning and at the end of the survey, when the information about HPV infection and vaccination had been given. The score is a scale from 1 to 10 , where 10 reflects the highest propensity toward the HPV vaccine.

\subsection{Statistical Analyses}

Statistical analysis was performed by means of JMP software (SAS, NC), version 13 and Microsoft Excel, version 2016 after generating data from the written questionnaires and Google Drive (CA, USA). Median and 25-75 percentiles for continuous variables, frequencies, and percentages for categorical variables were calculated. The possible association of baseline characteristics of young adults with knowledge and attitude scores was tested through univariable logistic regression. A $p$-value less than 0.05 was considered significant throughout the study. Multivariate logistic regression analysis was performed to identify the predictors of having high knowledge score or positive attitude score towards HPV vaccination. Only covariates that showed a significance level of $p$-value $<0.1$ in the univariate analysis were included in the multivariable regression model, using a backward stepwise algorithm. Given the high number of potential independent variables, a backward stepwise algorithm was used to identify the best-fitting subset of variables to use in the final regression model. In particular, Akaike's Information Criterion (AIC) was used to assess the models' fit and the model with the lowest AIC was selected for the multivariable analysis. $\beta$-coefficients ( $95 \%$ C.I.) and $p$-values were estimated.

\subsection{Ethics Approval and Consent to Participate}

In complying with the highest ethical standards, participants were informed that their participation was entirely voluntary and that they could withdraw at any moment. All data obtained through their participation was kept strictly confidential among the research team. In addition, an informed consent was obtained after explaining the nature of the study and its possible consequences of it. The study protocol was approved by the Liguria Regional Ethics Committee (P.R. 162REG2017) for the study coordination center. 


\section{Results}

\subsection{Participants' Characteristics}

A total of 680 young adults returned the self-administered questionnaires, giving a response rate of $100 \%$. Table 1 shows the participants' baseline characteristics. The median age of the participants was $20(25-75 p=19-21), 65.2 \%$ were female and $95.9 \%$ were Italian. A total of $97.1 \%$ declared to be students and only $2.9 \%$ were employed. A total of $24.5 \%$ of subjects had a graduate parent and $10.4 \%$ had at least one parent who was a health care operator. A total of $53.3 \%$ of the subjects consider their own economic status as good. As regards lifestyle habits, $23.1 \%$ and $56.6 \%$ of participants follow a specific diet and practice sports, respectively. Furthermore, $65 \%$ and $49.6 \%$ of young adults surfed the Internet and used the social networks up to $2 \mathrm{~h}$ a day, respectively. Among sexual habits, $61.8 \%$ of subjects had a partner at the time of the survey and $83.8 \%$ used contraceptive methods, the most reported of which was condom use (61.7\% of cases). Furthermore, $97.2 \%$ of participants were heterosexual. The median age of sexual debut and number of partners in the last year were $17(25-75 p=16-18)$ and 1 (25-75 $p=1-1)$, respectively.

Table 1. Baseline characteristics of the study's participants.

\begin{tabular}{|c|c|c|}
\hline & $N(\%)$ & Median $(25-75 p)$ \\
\hline Total & $680(100)$ & \\
\hline \multicolumn{3}{|l|}{ Variables } \\
\hline Age & & $20(19-21)$ \\
\hline \multicolumn{3}{|l|}{ Sex } \\
\hline Female & $443(65.15)$ & \\
\hline Male & $237(34.85)$ & \\
\hline \multicolumn{3}{|l|}{ Birthplace } \\
\hline Italy & $652(95.88)$ & \\
\hline NR & $2(0.29)$ & \\
\hline \multicolumn{3}{|l|}{ Parents' nationality } \\
\hline Italian parents & $515(75.74)$ & \\
\hline NR & $146(21.47)$ & \\
\hline \multicolumn{3}{|l|}{ Educational qualification of parents } \\
\hline Primary School Certificate & $2(0.39)$ & \\
\hline Secondary School Certificate & $153(29.94)$ & \\
\hline High School Diploma & $231(45.21)$ & \\
\hline University Degree & $125(24.46)$ & \\
\hline NR & $169(24.85)$ & \\
\hline Parents employed & $507(74.56)$ & \\
\hline NR & $159(23.38)$ & \\
\hline Parents healthcare worker & $50(10.35)$ & \\
\hline Student & $660(97.06)$ & \\
\hline NR & $20(2.94 \%)$ & \\
\hline University students & $597(90.45)$ & \\
\hline Health sciences & $186(31.26)$ & \\
\hline Other & $393(65.85)$ & \\
\hline NR & $18(2.87)$ & \\
\hline Worker & $147(21.62)$ & \\
\hline \multicolumn{3}{|l|}{ Economic status } \\
\hline Acceptable & $239(35.15)$ & \\
\hline Good & $364(53.53)$ & \\
\hline Poor & $77(11.32)$ & \\
\hline Diet & $157(23.09)$ & \\
\hline Physical activity & $385(56.62)$ & \\
\hline \multicolumn{3}{|l|}{ Surf the web } \\
\hline$\leq 2 \mathrm{~h}$ & $436(64.98)$ & \\
\hline $3-4 \mathrm{~h}$ & $184(27.42)$ & \\
\hline$\geq 5 \mathrm{~h}$ & $51(7.6)$ & \\
\hline
\end{tabular}


Table 1. Cont.

\begin{tabular}{|c|c|c|}
\hline & $N(\%)$ & Median $(25-75 p)$ \\
\hline \multicolumn{3}{|l|}{ Use of social network } \\
\hline$\leq 2 \mathrm{~h}$ & $330(49.55)$ & \\
\hline $3-4 \mathrm{~h}$ & $233(34.98)$ & \\
\hline$\geq 5 \mathrm{~h}$ & $103(15.47)$ & \\
\hline Religion & $449(66.03)$ & \\
\hline Catholics & $425(94.65)$ & \\
\hline \multicolumn{3}{|l|}{ Cohabitants } \\
\hline Parents & $580(85.29)$ & \\
\hline Friends & $60(8.82)$ & \\
\hline Alone & $28(4.12)$ & \\
\hline Sexual Partner & $12(1.76)$ & \\
\hline Sexual Partner & $420(61.76)$ & \\
\hline Use of contraceptive methods & $352(83.81)$ & \\
\hline \multicolumn{3}{|l|}{ Type of contraceptive method } \\
\hline Condom & $217(61.65)$ & \\
\hline Oral contraceptive & $112(31.82)$ & \\
\hline Vaginal ring & $25(7.10)$ & \\
\hline Intrauterine spiral & $4(1.14)$ & \\
\hline \multicolumn{3}{|l|}{ Sexual orientation } \\
\hline Heterosexual & $661(97.21)$ & \\
\hline Bisexual & $9(1.32)$ & \\
\hline Homosexual & $10(1.47)$ & \\
\hline Sexual Partners in the last year & & $1(1-1)$ \\
\hline Age of first sexual intercourse & & $17(16-18)$ \\
\hline Lifetime sexual partners & & $2(1-4)$ \\
\hline History of immunodeficiencies & $18(2.65)$ & \\
\hline History of STIs & $33(4.85)$ & \\
\hline History of HPV related lesions & $15(2.21)$ & \\
\hline
\end{tabular}

Frequencies and percentages for categorical variables and median and 25-75 percentiles for continuous variables, were calculated. Abbreviations: Non-responded, NR; sexually transmitted infections, STIs.

\subsection{Sources of Information about HPV}

A total of $80.4 \%$ of subjects had heard about HPV vaccine before the survey, in particular from a family member ( $43.7 \%$ of cases), Internet ( $24 \%$ of cases), teachers ( $25.1 \%$ of cases), and LHAs informative material (23.6\% of cases) (Table 2$)$.

Table 2. Sources of information about HPV.

\begin{tabular}{cc}
\hline Variables & $N(\%)$ \\
\hline Ever heard about HPV & $578(85.00)$ \\
Ever heard about HPV vaccine & $547(80.44)$ \\
Family member & $239(43.69)$ \\
Internet & $131(23.95)$ \\
Teacher & $137(25.05)$ \\
Information from the Local Health Agency & $129(23.58)$ \\
Healthcare workers of a vaccine center & $69(12.61)$ \\
Pediatrician/General Practitioner & $101(18.46)$ \\
Radio/TV & $89(16.27)$ \\
Gynecologist & $78(14.26)$ \\
Newspapers & $68(12.43)$ \\
Friends & $59(10.79)$ \\
Nurse & $27(4.94)$ \\
Other specialist doctor & $21(3.84)$ \\
Other Healthcare professionals & $21(3.84)$ \\
Sexual Partner & $16(2.93)$ \\
Colleagues & $10(1.83)$ \\
Pharmacist & $6(1.10)$ \\
\hline
\end{tabular}


Table 2. Cont.

\begin{tabular}{cc}
\hline Variables & $N(\%)$ \\
\hline Favourite source of information on HPV vaccines & \\
Trusted doctor & $387(56.91)$ \\
Internet & $330(48.53)$ \\
Books/paper material & $105(15.44)$ \\
Friends & $24(3.53)$ \\
\hline
\end{tabular}

Frequencies and percentages for categorical variables and median and 25-75 percentiles for continuous variables, were calculated.

\subsection{Knowledge of HPV Infection, Related Diseases, and Prevention}

The overall median knowledge score was 56.3\% (25-75 $p=40-68.8)$.

Most of the subjects answered correctly the statement that HPV is sexually transmitted (82.4\%) and that using condoms reduces the risk of HPV infection (86.2\%) (Table 3). Only $40.3 \%$ knew that $\mathrm{HPV}$ infection can be transmitted during pregnancy and delivery from mother to the child. Among risk factors of exposure to HPV infection, only about $50 \%$ of participants recognized the early sexual debut. A total of $77.5 \%$ of the subjects knew that HPV infects both females and males, but only $21.4 \%$ and $54 \%$ correlates HPV to penile and cervical cancers, respectively. In terms of benign diseases, the information that HPV can cause genital warts is known by $42.8 \%$ of subjects, and $80.4 \%$ are aware that both females and males can develop them. Only $52.7 \%$ and $48.7 \%$ of subjects are aware that HPV infection is widespread and can be transmitted by asymptomatic carriers. Furthermore, $40.9 \%$ of participants think that most infected subjects develop cancer. As regards HPV therapy, only $23.4 \%$ of participants knew that no specific treatments are available. Finally, $67.8 \%$ and $58.8 \%$ of young adults correctly answered the questions related to the indication of HPV vaccine targeting both females and males and the efficacy of HPV vaccine in adults who already had a sexual debut.

Table 3. Study's participants' knowledge about HPV infection, related diseases, and prevention.

\begin{tabular}{|c|c|c|c|c|c|c|c|}
\hline \multirow{2}{*}{ Knowledge Statement } & \multirow{2}{*}{ Response } & \multicolumn{2}{|c|}{ Correct } & \multicolumn{2}{|c|}{ Do not Know } & \multicolumn{2}{|c|}{ Wrong } \\
\hline & & $N$ & $\%$ & $N$ & $\%$ & $N$ & $\%$ \\
\hline HPV infection is transmitted through sexual intercourse & True & 560 & 82.35 & 95 & 13.97 & 25 & 3.68 \\
\hline If yes, early sexual debut increases the risk of contracting HPV & True & 263 & 46.96 & 127 & 22.68 & 170 & 30.36 \\
\hline If yes, using condoms reduces the risk of HPV transmission & True & 481 & 86.20 & 56 & 9.7 & 23 & 4.12 \\
\hline $\begin{array}{l}\text { If yes, a high number of sexual partners increases the risk of } \\
\text { contracting HPV }\end{array}$ & True & 383 & 68.39 & 97 & 17.33 & 80 & 14.28 \\
\hline $\begin{array}{l}\text { HPV infection can be transmitted from mother to child during } \\
\text { pregnancy and during delivery }\end{array}$ & True & 274 & 40.29 & 292 & 42.94 & 114 & 16.77 \\
\hline HPV can infect both males and females & True & 527 & 77.50 & - & - & 153 & 22.50 \\
\hline Disease associated with HPV in men: penile cancer & True & 114 & 21.39 & 221 & 41.46 & 198 & 37.14 \\
\hline Disease associated with HPV in women: cervical cancer & True & 367 & 53.97 & 172 & 25.29 & 141 & 20.74 \\
\hline HPV can lead to genital warts & True & 291 & 42.79 & 334 & 49.12 & 55 & 8.1 \\
\hline If yes, genital warts affect both male and female & True & 234 & 80.41 & - & - & 57 & 19.58 \\
\hline HPV infection is widespread & True & 358 & 52.65 & 246 & 36.18 & 76 & 11.17 \\
\hline Most HPV infected people develop cancer & False & 118 & 17.35 & 278 & 40.88 & 284 & 41.76 \\
\hline $\begin{array}{l}\text { HPV infection can be transmitted from a carrier to his/her } \\
\text { partner only if the carrier shows symptoms }\end{array}$ & False & 331 & 48.67 & 207 & 30.44 & 142 & 20.88 \\
\hline A person may be HPV-infected and not be aware of it & True & 452 & 66.47 & 180 & 26.47 & 48 & 7.06 \\
\hline There are no specific therapies for HPV infection & True & 159 & 23.38 & 319 & 46.91 & 202 & 29.71 \\
\hline Both males and females can be vaccinated against HPV & True & 461 & 67.79 & 3 & 0.44 & 216 & 31.76 \\
\hline The HPV vaccine is also effective in after starting sexual activity & True & 400 & 58.82 & 199 & 29.27 & 81 & 11.91 \\
\hline
\end{tabular}

For each knowledge statement, the correct answer is reported. Frequencies and percentages of correct, wrong and unknown answers were calculated. 
Table 4 shows the results of univariable logistic regression investigating the possible association between the characteristics of the participant young adults and the knowledge score. Variables significantly related to higher knowledge scores are: attending a healthcare university $(p<0.0001)$, using social networks up to $2 \mathrm{~h}$ a day $(p=0.0215)$, history of sexual transmitted infection and of HPV-related lesions ( $p=0.0349$ and $p=0.0290$, respectively), and having heard about HPV before the survey $(p=0.0035)$. Furthermore, family members and mass media as source of information about HPV are significantly related to worse knowledge scores ( $p=0.0501$ and $p=0.0762$, respectively). Gynecologists, instead, are reported as a source of information by young adults with significantly higher knowledge scores $(p=0.0014)$.

Table 4. Participants' knowledge and attitude scores stratified by their characteristics.

\begin{tabular}{|c|c|c|c|c|}
\hline Characteristics & $\begin{array}{l}\text { Knowledge Score } \\
\text { Median }(25-75 p)\end{array}$ & $p$-Value & $\begin{array}{c}\text { Attitude Score } \\
\text { Median }(25-75 p)\end{array}$ & $p$-Value \\
\hline \multicolumn{2}{|l|}{ Sex } & \multirow{3}{*}{0.7976} & & \multirow{3}{*}{0.0053} \\
\hline Female & $56.3(40-68.8)$ & & $4.5(4-5)$ & \\
\hline Male & $53.3(38.5-68.8)$ & & $4(4-5)$ & \\
\hline \multicolumn{2}{|l|}{ Birthplace } & \multirow{3}{*}{0.0716} & & \multirow{3}{*}{0.7724} \\
\hline Italy & $56.3(40-68.8)$ & & $4(4-5)$ & \\
\hline Other Countries & $48.35(32.8-64.08)$ & & $4.5(4-5)$ & \\
\hline \multicolumn{4}{|l|}{ Parents' nationality } & \multirow{3}{*}{0.0492} \\
\hline Italian & $53.3(37.5-64.7)$ & \multirow{2}{*}{0.5907} & $4(4-5)$ & \\
\hline No & $50(33.3-62.5)$ & & $4.5(4-5)$ & \\
\hline \multicolumn{2}{|l|}{ Educational qualification of parents } & \multirow{5}{*}{0.6626} & & \multirow{5}{*}{0.6358} \\
\hline Primary School Certificate & $44.85(25-64.7)$ & & $4.5(4-5)$ & \\
\hline Secondary School Certificate & $52.9(38-62.5)$ & & $4(4-5)$ & \\
\hline High School Diploma & $53.3(38.5-66.7)$ & & $4(4-5)$ & \\
\hline University Degree & $56.3(40-68.8)$ & & $4(4-5)$ & \\
\hline Parents employed & $53.3(37.5-64.7)$ & \multirow{2}{*}{0.9090} & $4(4-5)$ & \multirow{2}{*}{0.3643} \\
\hline No & $50(42.85-63.05)$ & & $4(4-4.13)$ & \\
\hline Parents healthcare worker & $58.15(35.1-73.73)$ & \multirow{2}{*}{0.1899} & $4(4-4.5)$ & \multirow{2}{*}{0.0103} \\
\hline No & $53.3(37.5-62.5)$ & & $4(4-5)$ & \\
\hline \multicolumn{2}{|l|}{ University students } & \multirow{3}{*}{$<0.0001$} & & \multirow{3}{*}{0.2365} \\
\hline Health sciences & $62.5(50-80)$ & & $4.5(4-5)$ & \\
\hline Other & $46.7(34.3-60)$ & & $4.5(4-5)$ & \\
\hline Worker & $53.3(40-68.8)$ & \multirow{2}{*}{0.7846} & $4(4-5)$ & \multirow{2}{*}{0.0211} \\
\hline No & $56.3(40-68.8)$ & & $4.5(4-5)$ & \\
\hline \multicolumn{2}{|l|}{ Economic status } & \multirow{4}{*}{0.3755} & & \\
\hline Acceptable & $53.3(38.5-68.8)$ & & $4(4-5)$ & \multirow{3}{*}{0.0031} \\
\hline Good & $56.3(40-68.8)$ & & $4.5(4-5)$ & \\
\hline Poor & $56.3(37.5-62.5)$ & & $4(4-4.5)$ & \\
\hline Diet & $53.3(38.75-66.7)$ & \multirow{2}{*}{0.6699} & $4(4-4.75)$ & \multirow{2}{*}{0.0004} \\
\hline No & $56.3(40-68.8)$ & & $4.5(4-5)$ & \\
\hline Physical activity & $56.3(40-68.8)$ & \multirow{2}{*}{0.3145} & $4(4-5)$ & \multirow{2}{*}{0.0577} \\
\hline No & $56.3(39.63-68.8)$ & & $4.5(4-5)$ & \\
\hline
\end{tabular}


Table 4. Cont.

\begin{tabular}{|c|c|c|c|c|}
\hline Characteristics & $\begin{array}{l}\text { Knowledge Score } \\
\text { Median }(25-75 p)\end{array}$ & $p$-Value & $\begin{array}{c}\text { Attitude Score } \\
\text { Median }(25-75 p)\end{array}$ & $p$-Value \\
\hline Surf the web & & \multirow{4}{*}{0.9326} & & \multirow{4}{*}{0.4214} \\
\hline$\leq 2 \mathrm{~h}$ & $56.3(40-68.8)$ & & $4(4-5)$ & \\
\hline $3-4 \mathrm{~h}$ & $56.3(40-68.8)$ & & $4(4-5)$ & \\
\hline$\geq 5 \mathrm{~h}$ & $53.3(40-64.3)$ & & $4(4-5)$ & \\
\hline Use of social network & & \multirow{4}{*}{0.0215} & & \multirow{4}{*}{0.0115} \\
\hline$\leq 2 \mathrm{~h}$ & $56.3(42.9-68.8)$ & & $4.5(4-5)$ & \\
\hline $3-4 \mathrm{~h}$ & $53.3(38.5-68.8)$ & & $4(4-5)$ & \\
\hline$\geq 5 \mathrm{~h}$ & $53.3(33.3-62.5)$ & & $4(4-4.5)$ & \\
\hline Religion & $53.3(40-68.8)$ & \multirow{2}{*}{0.4945} & $4(4-5)$ & \multirow{2}{*}{0.9570} \\
\hline No & $56.3(37.5-68.8)$ & & $4(4-5)$ & \\
\hline Cohabitants & & \multirow{5}{*}{0.5603} & & \multirow{5}{*}{0.4981} \\
\hline Parents & $56.3(40-66.7)$ & & $4(4-5)$ & \\
\hline Friends & $53.1(31.8-76.13)$ & & $4.5(4-5)$ & \\
\hline Alone & $64.6(32.85-82.4)$ & & $4.5(4-5)$ & \\
\hline Sexual Partner & $52.75(33.3-64.15)$ & & $4(4-4.5)$ & \\
\hline Sexual Partner & $56.3(40-68.8)$ & \multirow{2}{*}{0.5538} & $4(4-5)$ & \multirow{2}{*}{0.8926} \\
\hline No & $56.3(40-68.8)$ & & $4(4-5)$ & \\
\hline Contraceptive methods used & $53.55(40-66.7)$ & \multirow{2}{*}{0.8904} & $4(4-5)$ & \multirow{2}{*}{0.5055} \\
\hline No & $56.3(35.7-73.3)$ & & $4(4-5)$ & \\
\hline Sexual orientation & & \multirow{4}{*}{0.3461} & & \multirow{4}{*}{0.0841} \\
\hline Heterosexual & $56.3(40-68.8)$ & & $4(4-5)$ & \\
\hline Bisexual & $52.9(36.5-59.4)$ & & $5(4-5)$ & \\
\hline Homosexual & $72.8(35.95-88.2)$ & & $4.75(4-5)$ & \\
\hline \multicolumn{2}{|l|}{ Sexual Partners in the last year } & \multirow{3}{*}{0.5801} & & \multirow{3}{*}{0.1398} \\
\hline $0-2$ & $56.3(40-68.8)$ & & $4(4-5)$ & \\
\hline$\geq 3$ & $52.9(38.75-69.7)$ & & $5(4-5)$ & \\
\hline \multicolumn{2}{|l|}{ Age of first sexual intercourse } & \multirow{4}{*}{0.4739} & & \multirow{4}{*}{0.4767} \\
\hline $13-14$ & $54.8(35.1-65.2)$ & & $4.5(4-5)$ & \\
\hline $15-17$ & $53.3(38.25-68.8)$ & & $4(4-5)$ & \\
\hline$\geq 18$ & $56.3(41.7-68.8)$ & & $4(4-5)$ & \\
\hline \multicolumn{2}{|l|}{ Lifetime sexual partners } & \multirow{3}{*}{0.1491} & & \multirow{3}{*}{0.1929} \\
\hline $0-3$ & $56.3(38.5-68.28)$ & & $4(4-5)$ & \\
\hline$\geq 4$ & $56.3(40-68.8)$ & & $4.5(4-5)$ & \\
\hline History of immunodeficiency & $56.3(38.5-63.05)$ & \multirow{2}{*}{0.7165} & $4(3.88-4.13)$ & \multirow{2}{*}{0.0381} \\
\hline No & $56.3(40-68.8)$ & & $4(4-5)$ & \\
\hline History of STIs & $62.5(41.7-78.9)$ & \multirow{2}{*}{0.0349} & $4.5(4-5)$ & \multirow{2}{*}{0.1241} \\
\hline No & $56.3(40-68.8)$ & & $4(4-5)$ & \\
\hline History of HPV related lesions & $68.8(46.2-88.2)$ & 0.0290 & $4.5(4-5)$ & 0.4276 \\
\hline No & $56.3(40-68.8)$ & & $4(4-5)$ & \\
\hline
\end{tabular}


Table 4. Cont.

\begin{tabular}{|c|c|c|c|c|}
\hline Characteristics & $\begin{array}{l}\text { Knowledge Score } \\
\text { Median }(25-75 p)\end{array}$ & p-Value & $\begin{array}{c}\text { Attitude Score } \\
\text { Median }(25-75 p)\end{array}$ & $p$-Value \\
\hline Ever heard about HPV & $56.3(40-68.8)$ & \multirow{2}{*}{0.0035} & $4.5(4-5)$ & \multirow{2}{*}{$<0.0001$} \\
\hline No & $46.7(33.3-62.95)$ & & $4(3.5-4.3)$ & \\
\hline Ever heard about HPV vaccine & $56.3(41.7-68.8)$ & \multirow{2}{*}{0.0012} & $4.5(4-5)$ & \multirow{2}{*}{$<0.0001$} \\
\hline No & $50(34.5-62.5)$ & & $4(3.75-4.5)$ & \\
\hline \multicolumn{5}{|l|}{$\begin{array}{c}\text { Source of information on HPV } \\
\text { vaccine }\end{array}$} \\
\hline Family member & $56.3(40-66.7)$ & \multirow{2}{*}{0.0501} & $4.5(4-5)$ & \multirow{2}{*}{0.6436} \\
\hline No & $57.95(42.9-73.3)$ & & $4.5(4-5)$ & \\
\hline Internet & $58.8(42.9-73.3)$ & \multirow{2}{*}{0.2843} & $4.5(4-5)$ & \multirow{2}{*}{0.8713} \\
\hline No & $56.3(40.43-68.8)$ & & $4.5(4-5)$ & \\
\hline Teacher & $60(43.8-72.8)$ & \multirow{2}{*}{0.0773} & $4.5(4-5)$ & \multirow{2}{*}{0.0100} \\
\hline No & $56.3(40-68.8)$ & & $4.5(4-5)$ & \\
\hline $\begin{array}{l}\text { Information from the Local Health } \\
\text { Agency }\end{array}$ & $58.8(46.2-70.6)$ & \multirow[t]{2}{*}{0.1671} & $4.5(4-5)$ & \multirow[t]{2}{*}{0.0081} \\
\hline No & $56.3(40-68.8)$ & & $4.5(4-5)$ & \\
\hline $\begin{array}{c}\text { Healthcare workers of a vaccine } \\
\text { center }\end{array}$ & $56.3(43.8-62.5)$ & \multirow[t]{2}{*}{0.2754} & $4.5(4-5)$ & \multirow[t]{2}{*}{0.6951} \\
\hline No & $56.3(41.27-70.6)$ & & $4.5(4-5)$ & \\
\hline Pediatrician/General Practitioner & $56.3(43.8-68.8)$ & \multirow{2}{*}{0.6522} & $5(4-5)$ & \multirow{2}{*}{0.0061} \\
\hline No & $56.3(40-68.8)$ & & $4.5(4-5)$ & \\
\hline Radio/TV & $53.8(33.3-65.7)$ & \multirow{2}{*}{0.0762} & $4.5(4-5)$ & \multirow{2}{*}{0.4692} \\
\hline No & $56.3(43.57-70.6)$ & & $4.5(4-5)$ & \\
\hline Gynecologist & $62.5(46.7-81.57)$ & \multirow{2}{*}{0.0014} & $4.5(4-5)$ & \multirow{2}{*}{0.0564} \\
\hline No & $56.3(40-68.8)$ & & $4.5(4-5)$ & \\
\hline Newspapers & $56.3(35.4-70.15)$ & \multirow{2}{*}{0.7765} & $4.5(4-5)$ & \multirow{2}{*}{0.3178} \\
\hline No & $56.3(42.9-68.8)$ & & $4.5(4-5)$ & \\
\hline Friends & $57.1(43.8-66.7)$ & \multirow{2}{*}{0.5906} & $4.5(4-5)$ & \multirow{2}{*}{0.4726} \\
\hline $\mathrm{No}$ & $56.3(40-68.8)$ & & $4.5(4-5)$ & \\
\hline
\end{tabular}

For each knowledge statement, one point was given for a correct answer (true or false) and zero points if a wrong answer or "Do not know" was reported. The knowledge score is the number of correct answers/number of knowledge statements $\times 100$. Attitude score of each subject was estimated through a five-point Likert scale (5 points-Strongly Agree, 4 point-Agree, 3 points-Neutral, 2 points-Disagree, 1 points-Strongly Disagree) and is the median of the total points was calculated for every participant (range $=1.0$ to 5.0). The univariable logistic regression tested the possible association of baseline characteristics of young adults with knowledge and attitude scores. A $p$-value less than 0.05 was considered significant.

\subsection{Attitudes about HPV Infection and Prevention}

The overall median attitude score was as high as $4(25-75 p=4-5)$. Only $49.7 \%$ of participants agree or strongly agree that during the own life he/she will have high probability to be exposed to HPV infections (Table 5). A total of $93.8 \%$ of subjects, instead, are aware that HPV can cause serious diseases. As regards the favorite source of information and opinion to get vaccinated, the most reported were trusted doctors $(85.3 \%)$ and teachers $(90.4 \%)$, followed by parents and partners $(51.8 \%$ and $39.9 \%$, respectively). About safety concern, $76.5 \%$ of partipants believe that HPV vaccine is safe. Furthermore, $83.5 \%$ agree or strongly agree to have their own child vaccinated. 
Table 5. Study's participants' attitudes toward HPV infections, related diseases, and prevention statements.

\begin{tabular}{|c|c|c|c|c|c|c|c|c|c|c|}
\hline \multirow[t]{2}{*}{ Attitude Statement } & \multicolumn{2}{|c|}{$\begin{array}{l}\text { Strongly } \\
\text { Agree }\end{array}$} & \multicolumn{2}{|c|}{ Agree } & \multicolumn{2}{|c|}{ Neutral } & \multicolumn{2}{|c|}{ Disagree } & \multicolumn{2}{|c|}{ Strongly Disagree } \\
\hline & $n$ & $\%$ & $n$ & $\%$ & $n$ & $\%$ & $n$ & $\%$ & $n$ & $\%$ \\
\hline $\begin{array}{l}\text { I believe that Papillomavirus } \\
\text { (HPV) can cause serious diseases }\end{array}$ & 380 & 55.88 & 258 & 37.94 & 29 & 4.26 & 8 & 1.17 & 5 & 0.74 \\
\hline $\begin{array}{l}\text { I believe that I will be exposed to } \\
\text { HPV infection during my life }\end{array}$ & 77 & 11.32 & 261 & 38.38 & 225 & 33.09 & 89 & 13.09 & 28 & 4.12 \\
\hline $\begin{array}{l}\text { I believe anti-HPV vaccines are } \\
\text { capable of preventing the } \\
\text { occurrence of cervical cancer and } \\
\text { genital warts }\end{array}$ & 338 & 49.70 & 280 & 41.18 & 56 & 8.24 & 6 & 0.88 & - & \\
\hline $\begin{array}{l}\text { I believe the anti-HPV vaccination } \\
\text { must be mandatory for boys and } \\
\text { girls before the sexual debut and } \\
\text { for at risk subjects }\end{array}$ & 332 & 48.82 & 238 & 35.10 & 84 & 12.39 & 16 & 2.36 & 10 & 1.48 \\
\hline $\begin{array}{l}\text { I believe my parents' favorable } \\
\text { opinion is essential to decide to get } \\
\text { vaccinated against HPV * }\end{array}$ & 114 & 18.57 & 204 & 33.22 & 169 & 27.52 & 83 & 13.52 & 44 & 7.16 \\
\hline $\begin{array}{l}\text { I believe that the favorable opinion } \\
\text { of my partner is essential to decide } \\
\text { to get vaccinated against HPV }\end{array}$ & 77 & 11.32 & 194 & 28.53 & 175 & 25.73 & 128 & 18.82 & 106 & 15.59 \\
\hline $\begin{array}{c}\text { I believe it is useful to talk to my } \\
\text { doctor about HPV infections and } \\
\text { other sexually transmitted } \\
\text { infections }\end{array}$ & 243 & 35.73 & 337 & 49.55 & 87 & 12.79 & 8 & 1.18 & 5 & 0.73 \\
\hline $\begin{array}{l}\text { I believe it is useful to talk about } \\
\text { HPV infections and other sexually } \\
\text { transmitted infections at school }\end{array}$ & 364 & 53.53 & 251 & 36.91 & 58 & 8.53 & 5 & 0.73 & 2 & 0.29 \\
\hline $\begin{array}{l}\text { I believe if I have children I get } \\
\text { them vaccinated against HPV }\end{array}$ & 324 & 47.65 & 244 & 35.88 & 102 & 15 & 10 & 1.47 & - & \\
\hline $\begin{array}{l}\text { I believe the anti-HPV vaccine is } \\
\text { safe }\end{array}$ & 218 & 32.1 & 302 & 44.41 & 139 & 20.44 & 17 & 2.5 & 4 & 0.59 \\
\hline
\end{tabular}

Legend: * N. 66 (9.71\%) subjects did not answer. For each attitude statement, the answer is reported. Frequencies and percentages of "strongly agree", "agree", "neutral", "disagree", "strongly disagree" answers were calculated.

Table 4 shows the results of univariable logistic regression investigating the possible association between the characteristics of the participant young adults and the attitude score. Significantly higher attitude scores were reported among subjects with foreign parents, without parents who are healthcare workers $(p=0.0103)$, who are not employed $(p=0.0211)$, who reported a good economic status $(p=0.0031)$, who do not follow a specific diet $(p=0.0004)$, who use social network up to $2 \mathrm{~h}$ a day $(p=0.0115)$, those without immunodeficiencies $(p=0.0381)$, and those who heard about HPV before the survey $(p<0.0001)$. As regards the source of information about HPV vaccine, subjects who reported teachers, LHAs informative material, pediatricians/general practitioners, had significantly higher attitude scores $(p=0.0100, p=0.0081$, and $p=0.0061$, respectively).

\subsection{Propensity toward HPV Vaccination}

The median propensity score before and after the educational intervention was stable and high as $9(25-75 p=8-10)$.

\subsection{Multivariate Analysis}

The results of the multivariate analysis predicting high knowledge and attitude scores are presented in Tables 6 and 7, respectively. The predictors of high knowledge are attending Healthcare University, using social network $\leq 2 \mathrm{~h} /$ day, having a history of STIs, and having heard about HPV and anti-HPV 
vaccine before the survey. As regards predictors of high attitude score, a good economic status and having heard about HPV before the survey are predicted to have more positive attitudes towards HPV vaccine, while having Italian parents, being employed, and a parent who is/was a healthcare worker are predicted to have worse attitudes. Both the models significantly help in predicting knowledge and attitude scores since the $p$-values of the F-test are $<0.0001$.

Table 6. Multivariate analysis for predicting knowledge score.

\begin{tabular}{ccccc}
\hline Characteristics & $\begin{array}{c}\beta \text {-Coefficient } \\
\text { (95\% C.I.) }\end{array}$ & $\begin{array}{c}\text { 95\% C.I. Lower } \\
\text { Limit }\end{array}$ & $\begin{array}{c}\text { 95\% C.I. Upper } \\
\text { Limit }\end{array}$ & $p$-Value \\
\hline University: health sciences & 6.713 & 4.508 & 8.918 & $<0.0001$ \\
Use of social network $\leq 2$ h/day & 2.691 & 0.547 & 4.834 & 0.0141 \\
History of STIs & 4.208 & 0.114 & 8.302 & 0.0440 \\
Ever heard about HPV & 8.789 & 2.397 & 15.181 & 0.0072 \\
Ever heard about HPV vaccine & 6.061 & 1.262 & 10.859 & 0.0135 \\
\hline
\end{tabular}

Covariates significant at 0.1 in the univariate analysis were evaluated for inclusion in multivariable regression model, using a backward stepwise algorithm.

Table 7. Multivariate analysis for predicting attitude score.

\begin{tabular}{ccccc}
\hline Characteristics & $\begin{array}{c}\beta \text {-Coefficient } \\
\text { (95\% C.I.) }\end{array}$ & $\begin{array}{c}\text { 95\% C.I. Lower } \\
\text { Limit }\end{array}$ & $\begin{array}{c}\text { 95\% C.I. Upper } \\
\text { Limit }\end{array}$ & $p$-Value \\
\hline Italian parents & -0.1548 & -0.3031 & -0.0065 & 0.0408 \\
Worker & -0.0911 & -0.1610 & -0.0213 & 0.0106 \\
Economic status: good & 0.0713 & 0.0178 & 0.1246 & 0.0089 \\
Diet & -0.1473 & -0.2126 & -0.0821 & $<0.0001$ \\
Ever heard about HPV & 0.1715 & 0.1018 & 0.2413 & $<0.0001$ \\
Parents healthcare worker & -0.1132 & -0.2001 & -0.0263 & 0.0108 \\
\hline
\end{tabular}

Covariates that were significant at 0.1 in the univariate analysis were evaluated for inclusion in multivariable regression model, using a backward stepwise algorithm.

\section{Discussion}

To the best of our knowledge, this is one of the first studies to quantitatively investigate knowledge and attitudes about HPV, and propensity towards HPV vaccination before and after a formative moment, in young adults students of both genders living in a high gross domestic product (GDP) country such as Italy, where a dynamicity in the objectives and targets of HPV vaccination by public health since its introduction in 2007 was observed. This study was performed not only in undergraduates attending health sciences schools, but also in other university students.

Young adults are a category at risk of sexually transmitted HPV infection. Since HPV has a causative role in serious and frequent diseases, such as cancers and genital warts, respectively, interventions to prevent low and high-risk types of HPV infections are urgently warranted; indeed, vaccinating both men and women against HPV is crucial to protect against HPV-related cancers and other diseases.

Recent international recommendation on HPV vaccination have included additional age classes, not only adolescents of both genders (aged 11-12 years), but also females 13-26 years-old who have not been previously vaccinated or who have not completed the vaccine series, and males aged 13-21 years and 22-26 years with special conditions or who want to protect themselves from the disease [17,18]. The current Italian National Vaccine Prevention Plan (NVPP) 2017-2019 extended the vaccination program to include pre-adolescent males (aged between 11 and 12 years) and at-risk subjects (men who engage in same-sex sexual behaviors) [14]. Furthermore, the NVPP recommends a multi-cohort immunization strategy, preferably targeting 25 years-old young adult females who begin cervical cancer screening. Based on the current vaccination plans and the need to implement knowledge and 
attitude of young adults of both gender, an overall approach is desired. Indeed, it is of note that HPV coverage rates are suboptimal in both genders in many developed countries, including Italy [19].

An evaluation of what young adults know about the threat of HPV and believe about HPV prevention can offer possible solutions to remedy the underutilization of the HPV vaccine in a population at high risk for contracting this preventable infection and to explore innovative strategies. The findings are, therefore, relevant at the light of better understanding and comparing educational needs and attitudes toward HPV infection and prevention in one of the HPV vaccine targets [20-22]. Furthermore, the interviewed subset including health sciences students, allowed estimating knowledge needs and main attitudes of future healthcare workers and counsellors.

Our findings highlight, on one side, insufficient knowledge of undergraduate students on HPV infection and HPV- related diseases, on the other side, a substantial positive attitude toward the vaccine. Gaps on HPV knowledge were detected in previous studies enrolling study population similar to our study population for demographic characteristics [23-26]. In our survey, a not negligible percentage of students had low consciousness about the impact of HPV infection in terms of spread, the routes of infection, and risk factors, such as early sexual debut, the role of HPV in causing penile cancer and genital warts, and the unavailability of specific therapeutic treatment. This would confirm the need to promote educational programs for young subjects and introducing changes in the current curriculum of university students attending health sciences schools, in order to increase understanding about HPV of future healthcare professionals. However, as expected, higher knowledge was detected in health sciences students' respect to undergraduates attending other academic course $(p<0.0001)$. Results worthy of highlighting are that more than $93 \%$ affirmed that HPV can be implicated in developing serious disease but only $49.7 \%$ consider themselves at risk of exposure to HPV. These results are comparable with those described by Villanueva et al. who recently investigated knowledge, attitudes, and intentions towards HPV among nursing students in Spain [25]. As regards attitudes towards HPV vaccine, more than $90 \%$ and $76 \%$ of participants consider HPV vaccine effective and safe, respectively. In a very recent Italian cross-sectional study that assessed nursing students' knowledge and attitudes about HPV infection and vaccination, only $20.5 \%$ of subjects considered very safe the HPV vaccine [27]. The abovementioned Spanish study also investigated attitudes towards HPV vaccine efficacy and safety, finding that $66.5 \%$ and $65.4 \%$ of students agree or strongly agree that HPV is capable of preventing the occurrence of cervical cancer and that side effects are reasonable, respectively [25]. We also investigated the willingness of participants considered as potential future parents to get their own child immunized against HPV and only $83.5 \%$ agree or strongly agree with this sentence. This observation is of concern since it demonstrates that the high consciousness of the causal role of HPV in determining serious diseases, such as cancers, is not a sufficient factor in determining recommended vaccine compliance.

Among young adults characteristics, parents' nationality, educational qualification, and employment were investigated in relation to knowledge and attitude scores. The knowledge score resulted higher, although not statistically significant, in young adults with healthcare worker parents, while the attitude score was higher for subjects with parents who are employed in other sectors. This observation could be linked to the well-known largely suboptimal compliance of healthcare workers to vaccines $[28,29]$. Furthermore, considering the parents' nationality, knowledge scores of young subjects was similar between those with Italian parents and those without. On the contrary, the attitude score was higher in those with foreigner parents $(p=0.0491)$, who mainly come from developing countries. A possible explanation could be a better propensity by the foreign families towards Italian healthcare services, including prevention. As regards lifestyles, the young who follow specific nutritional regimen had significantly lower attitude score $(p=0.0044)$, confirmed by multivariate analysis $(p<0.0001)$, this could be explained by the fact that those who engage in specific behaviors oriented around 'the natural' is often hesitant or refuse vaccines [30]. Surprisingly, physical activity was related neither to higher knowledge nor to attitude scores. Although healthy lifestyles are expected to be related to better compliance to preventive measures. Among sexual habits, $83.8 \%$ of subjects who had a partner at the time of the survey (61.8\% of participating young adults) used contraceptive methods, the most 
represented of which was condom use $(61.7 \%)$, followed by oral contraceptive (31.8\%). Furthermore, the median age of sexual debut was $17(25-75 p=16-18)$, with a median of lifetime sexual partners of $2(25-75 p=1-4)$. These findings are substantially comparable with the observations obtained in other European countries [22,25]. Considering sexual orientation, $1.3 \%$ and $1.5 \%$ were bisexual and homosexual, respectively. Of relevance, homosexual surveyed subjects demonstrated higher knowledge than heterosexual and bisexual subjects, although this result has to be interpreted with caution because of the scarce number of surveyed homosexual and bisexual subjects. A possible explanation could be the higher attention toward to health and prevention tools by homosexuals. History of STIs and HPV-related lesions was also investigated, showing that only $4.9 \%$ and $2.2 \%$ of subjects were diagnosed for the abovementioned diseases, respectively. Furthermore, the history of STIs was found as predictor of high knowledge score at the multivariate analysis $(p=0.0440)$. This observation could be linked to the previous contact of affected subjects with the healthcare system which could have favored the acquisition of knowledge on this topic.

Before the educational moment, subjects were asked to declare if they have heard about HPV previously. Our findings revealed that a high percentage of young $(80 \%)$ already knew this infection, which is well up rates reported in other published research [31-33] and significantly predicts both higher knowledge and attitude scores $(p=0.0072$ and $p<0.001)$. In particular, family members, Internet, teachers, and LHAs' informative material were the most frequently reported sources of information. Surfing the web and the use of social networks were also investigated, showing that using social network $\leq 2 \mathrm{~h} /$ day is among the predictors of better knowledge on HPV compared to higher use $(p=0.0141)$. This finding suggests that social networks can also disseminate misleading messages on HPV. Nevertheless, the increasing pervasiveness of social media, such as Facebook, as powerful communication channels means that they can potentially be used to effectively reach young people. Therefore, public health should better communicate messages through existing networks and engage in on-going dialogue with users [34-36].

Our study also deepened attitudes regarding the favorite sources of information about HPV of participating subjects, finding that talking about HPV with teachers and trusted doctor is considered very useful by young adults, while only $51.8 \%$ and $39.9 \%$ of participants believe that parents' and partner's opinions are essential to decide to get vaccinated against HPV. These answers confirm the role of physicians and teachers recognized by young adults in spreading health information including sensitive topics such as STIs. Of note, the majority of participants (83.92\%) agree or strongly agree to make compulsory HPV vaccine for boys and girls before the sexual debut and for at risk subjects. This is of interest in countries such as Italy where a recent law introduced the compulsory of some vaccines, excluding HPV [37].

In order to evaluate the efficacy of educational intervention in implementing the propensity of young adults toward HPV vaccine, we estimated it through a score before and after the administration of a written text summarizing the available evidences on HPV infection, related diseases and prevention. The score resulted very high (median $=9,25-75 p=8-10$ ) and remained stable after the educational session. A recent meta-analysis that assessed the effectiveness of interventions targeting HPV vaccine initiation and completion among children, adolescents, and young adults aged 9-26 years support behavioral and informational interventions, including education (e.g., exercises, audit and feedback, video intervention, peer/medical narrative), educational websites tailored to baseline knowledge, and brochures/factsheets, for HPV vaccine initiation and behavioral interventions for completion [38]. Considering the surveyed subset of health sciences students, and their future role in counselling on prevention themes, a comparison with the results of a recent published study by Berenson et al. could be conducted. The authors assessed the effects of an educational program by means of a single lecture and delivered by an expert and found that this can improve medical students' attitudes and comfort with HPV vaccine counseling [39]. This evidence suggests that short educational interventions are already efficacious, but the presence of an expert open to discussion allows obtaining better results than reading informative material alone. 
The study limits are the nature of self-reported data collected from the participants, which may be compromised by the respondents' memory of experiences of interest. Furthermore, since northern and southern regions were involved in the enrollments, the representativeness of young adults living in the Central Italian regions is lacking. Despite these limitations, this survey obtained a very high response rate, demonstrating the strong interest in HPV topic. As regards education, the self-learning session could be improved by focus groups and other interactive methods. Nevertheless, academic public health teaching includes HPV burden and prevention among treated themes.

\section{Conclusions}

The results of the current study demonstrates that Italian undergraduates show suboptimal knowledge on HPV and good attitudes. Since they represent both the target of HPV vaccine and future healthcare workers, the implementation of training about HPV infection, its related diseases, and prevention tools are needed to support the important role they play in the prevention of STIs, some of which are related to the occurrence of cancer. Universities represent a privileged setting to spread information about HPV to the target audience and young adults recognize teachers together with trusted doctors as the favorite source of information. Improving students' knowledge may have favorable implications in increasing vaccine coverage rates.

Author Contributions: Conceptualization:, C.T. and G.I.; Methodology: C.T. and F.A.; Formal analysis: C.T.; Investigation: S.T., L.S., P.D. and A.M.B.; Resources: S.T., L.S., P.D. and A.M.B.; Data curation: C.T., F.V. and B.D.S.; Writing-Original draft preparation: C.T. and C.C.; Writing-Review and editing: C.T., F.A., G.I and D.A.; Supervision: F.A. and G.I.; Project administration: C.T. and G.I. All authors have read and agreed to the published version of the manuscript.

Funding: The research was conducted with the support of Sanofi Pasteur MSD, who funded a fixed-term contract for an assistant professor in public health. The funding sources neither influenced the design of the study nor the analysis of the results.

Acknowledgments: The authors would like to thank the students attending Universities of Genoa and Bari for their participation in the study.

Conflicts of Interest: Giancarlo Icardi is the principal investigator of this national multicenter study. The research staff included the fixed-term assistant professor funded by Sanofi Pasteur MSD. The other authors have no known competing financial interests nor personal relationships that could have appeared to influence the work reported in this paper. The funders had no role in the design of the study; in the collection, analyses, or interpretation of data; in the writing of the manuscript; or in the decision to publish the results.

\section{References}

1. Satterwhite, C.L.; Torrone, E.; Meites, E.; Dunne, E.F.; Mahajan, R.; Ocfemia, M.C.; Su, J.; Xu, F.; Weinstock, H. Sexually transmitted infections among US women and men: Prevalence and incidence estimates, 2008. Sex. Transm. Dis. 2013, 40, 187-193. [CrossRef] [PubMed]

2. WHO. Human Papillomavirus (HPV) and Cervical Cancer. Available online: https://www.who.int/newsroom/fact-sheets/detail/human-papillomavirus-(hpv)-and-cervical-cancer (accessed on 20 October 2019).

3. Bosch, F.X.; de Sanjosé, S. Chapter 1: Human papillomavirus and cervical cancer-burden and assessment of causality. J. Natl. Cancer Inst. Monogr. 2003, 31, 3-13. [CrossRef] [PubMed]

4. Serrano, B.; Brotons, M.; Bosch, F.X.; Bruni, L. Epidemiology and burden of HPV-related disease. Best Pract. Res. Clin. Obstet. Gynaecol. 2018, 47, 14-26. [CrossRef] [PubMed]

5. Bray, F.; Ferlay, J.; Soerjomataram, I.; Siegel, R.L.; Torre, L.A.; Jemal, A. Global cancer statistics 2018: GLOBOCAN estimates of incidence and mortality worldwide for 36 cancers in 185 countries. CA Cancer J. Clin. 2018, 68, 394-424. [CrossRef] [PubMed]

6. Schiffman, M.; Kjaer, S.K. Chapter 2: Natural history of anogenital human papillomavirus infection and neoplasia. J. Natl. Cancer Inst. Monogr. 2003, 31, 14-19. [CrossRef] [PubMed]

7. Winkelestein, W., Jr. Smoking and cancer of the uterine cervix: Hypotesis. Am. J. Epidemiol. 1977, 106, 257-259. [CrossRef]

8. Prokopczyk, B.; Cox, J.E.; Hoffmann, D.; Waggoner, S.E. Identification of tobacco specific carcinogen in the cervical mucus of smokers and nonsmokers. J. Natl. Cancer Inst. 1997, 89, 868-873. [CrossRef] 
9. Brotherton, J.M.L. Impact of HPV vaccination: Achievements and future challenges. Papillomavirus Res. 2019, 7, 138-140. [CrossRef]

10. Kent, A. HPV Vaccination and Testing. Rev. Obstet. Gynecol. 2010, 3, 33-34.

11. Prue, G.; Baker, P.; Graham, D.; Nutting, C.; Greenhouse, P.; Lawler, M. It is time for universal HPV vaccination. Lancet 2018, 392, 913-914. [CrossRef]

12. WHO. Regional Office for Europe. Available online: http://www.euro.who.int/_data/assets/pdf_file/0010/ 356842/QA_HPV_General_EN.pdf (accessed on 20 October 2019).

13. Ministero Della Salute. Campagna di Comunicazione Contro il Papilloma Virus-2008. Available online: http://www.salute.gov.it/portale/news/p3_2_6_1_1.jsp?lingua=italiano\&menu=campagne\&p= dacampagne\&id=42 (accessed on 20 October 2019).

14. Intesa tra il Governo, le Regioni e le Province Autonome di Trento e Bolzano sul Documento recante "Piano Nazionale Prevenzione Vaccinale (PNPV) 2017-2019". Intesa ai Sensi Dell'Articolo 8, Comma 6, Della Legge 5 Giugno. 2003, n. 131. Available online: http://www.salute.gov.it/imgs/C_17_pubblicazioni_2571_allegato.pdf (accessed on 20 October 2019).

15. Soe, N.N.; Ong, J.J.; Ma, X.; Fairley, C.K.; Latt, P.M.; Jing, J.; Cheng, F.; Zhang, L. Should human papillomavirus vaccination target women over age 26 , heterosexual men and men who have sex with men? A targeted literature review of cost-effectiveness. Hum. Vaccine Immunother. 2018, 14, 3010-3018. [CrossRef] [PubMed]

16. Ng, S.S.; Hutubessy, R.; Chaiyakunapruk, N. Systematic review of cost-effectiveness studies of human papillomavirus (HPV) vaccination: 9-Valent vaccine, gender-neutral and multiple age cohort vaccination. Vaccine 2018, 36, 2529-2544. [CrossRef] [PubMed]

17. Kim, D.K.; Hunter, P.; Advisory Committee on Immunization Practices. Recommended Adult Immunization Schedule, United States, 2019. Ann. Intern. Med. 2019, 170, 182. [CrossRef] [PubMed]

18. Saslow, D.; Andrews, K.S.; Manassaram-Baptiste, D.; Loomer, L.; Lam, K.E.; Fisher-Borne, M.; Smith, R.A.; Fontham, E.T.; American Cancer Society Guideline Development Group. Human papillomavirus vaccination guideline update: American Cancer Society guideline endorsement. CA Cancer J. Clin. 2016, 66, 375-385. [CrossRef] [PubMed]

19. Trucchi, C.; Costantino, C.; Restivo, V.; Bertoncello, C.; Fortunato, F.; Tafuri, S.; Amicizia, D.; Martinelli, D.; Paganino, C.; Piazza, M.F.; et al. Immunization Campaigns and Strategies against Human Papillomavirus in Italy: The Results of a Survey to Regional and Local Health Units Representatives. Biomed Res. Int. 2019, 4, 6764154. [CrossRef] [PubMed]

20. Herman, R.; McNutt, L.A.; Mehta, M.; Salmon, D.A.; Bednarczyk, R.A.; Shaw, J. Vaccination perspectives among adolescents and their desired role in the decision-making process. Hum. Vaccine Immunother. 2019, 15, 1752-1759. [CrossRef]

21. Caskey, R.; Lindau, S.T.; Alexander, G.C. Knowledge and early adoption of the HPV vaccine among girls and young women: Results of a national survey. J. Adolesc. Health 2009, 45, 453-462. [CrossRef]

22. Jeannot, E.; Viviano, M.; Follonier, M.C.; Kaech, C.; Oberhauser, N.; Mpinga, E.K.; Vassilakos, P.; Kaiser, B.; Petignat, P. Human Papillomavirus Infection and Vaccination: Knowledge, Attitude and Perception among Undergraduate Men and Women Healthcare University Students in Switzerland. Vaccines 2019, 7, 130. [CrossRef]

23. Topan, A.; Ozturk, O.; Eroglu, H.; Bahadir, O.; Harma, M.; Harma, M.I. Knowledge level of working and student nurses on cervical cancer and human papilloma virus vaccines. Asian Pac. J. Cancer Prev. 2015, 16, 2515-2519.

24. Uzunlar, Ö.; Özyer, Ş.; Başer, E.; Toğrul, C.; Karaca, M.; Güngör, T. A survey on human papillomavirus awareness and acceptance of vaccination among nursing students in a tertiary hospital in Ankara, Turkey. Vaccine 2013, 31, 2191-2195. [CrossRef]

25. Villanueva, S.; Mosteiro-Miguéns, D.G.; Domínguez-Martís, E.M.; López-Ares, D.; Novío, S. Knowledge, Attitudes, and Intentions towards Human Papillomavirus Vaccination among Nursing Students in Spain. Int. J. Environ. Res. Public Health 2019, 16, 4507. [CrossRef] [PubMed]

26. Dany, M.; Chidiac, A.; Nassar, A.H. Human papillomavirus vaccination: Assessing knowledge, attitudes, and intentions of college female students in Lebanon, a developing country. Vaccine 2015, 33, 1001-1007. [CrossRef] [PubMed] 
27. Pelullo, C.P.; Esposito, M.R.; Di Giuseppe, G. Human Papillomavirus Infection and Vaccination: Knowledge and Attitudes among Nursing Students in Italy. Int. J. Environ. Res. Public Health 2019, 16, 1770. [CrossRef] [PubMed]

28. Genovese, C.; Picerno, I.A.M.; Trimarchi, G.; Cannavò, G.; Egitto, G.; Cosenza, B.; Merlina, V.; Icardi, G.; Panatto, D.; Amicizia, D.; et al. Vaccination coverage in healthcare workers: A multicenter cross-sectional study in Italy. J. Prev. Med. Hyg. 2019, 60, E12-E17. [PubMed]

29. Durando, P.; Alicino, C.; Dini, G.; Barberis, I.; Bagnasco, A.M.; Iudici, R.; Zanini, M.; Martini, M.; Toletone, A.; Paganino, C.; et al. Determinants of adherence to seasonal influenza vaccination among healthcare workers from an Italian region: Results from a cross-sectional study. BMJ Open 2016, 6, e010779. [CrossRef] [PubMed]

30. Attwell, K.; Smith, D.T.; Ward, P.R. The Unhealthy Other': How vaccine rejecting parents construct the vaccinating mainstream. Vaccine 2018, 36, 1621-1626. [CrossRef] [PubMed]

31. Blake, K.D.; Ottenbacher, A.J.; Finney Rutten, L.J.; Grady, M.A.; Korbrin, S.C.; Jacobson, R.M.; Hesse, B.W. Predictors of human papillomavirus awareness and knowledge 2013: Gaps and opportunities for targeted communication strategies. Am. J. Prev. Med. 2015, 48, 402-410. [CrossRef]

32. McBride, K.R.; Singh, S. Predictors of Adults' Knowledge and Awareness of HPV, HPV-Associated Cancers, and the HPV Vaccine. Health Educ. Behav. 2018, 45, 68-76. [CrossRef]

33. Sherman, S.M.; Nailer, E.; Minshall, C.; Coombes, R.; Copper, J.; Redman, C.W. Awareness and knowledge of HPV and cervical cancer in female students: A survey (with a cautionary note). J. Obstet. Gynaecol. 2016, 36, 76-80. [CrossRef]

34. Subasinghe, A.K.; Nguyen, M.; Wark, J.D.; Tabrizi, S.N.; Garland, S.M. Targeted Facebook Advertising is a Novel and Effective Method of Recruiting Participants into a Human Papillomavirus Vaccine Effectiveness Study. JMIR Res. Protoc. 2016, 5, e154. [CrossRef]

35. Keelan, J.; Pavri, V.; Balakrishnan, R.; Wilson, K. An analysis of the Human Papilloma Virus vaccine debate on MySpace blogs. Vaccine 2010, 28, 1535-1540. [CrossRef] [PubMed]

36. Amicizia, D.; Domnich, A.; Gasparini, R.; Bragazzi, N.L.; Lai, P.L.; Panatto, D. An overview of current and potential use of information and communication technologies for immunization promotion among adolescents. Hum Vaccine Immunother. 2013, 9, 2634-2642. [CrossRef] [PubMed]

37. Ministero della Salute. Decreto legge 7 giugno 2017, n. 73, Disposizioni Urgenti in Materia di Prevenzione Vaccinale, Come Modificato Dalla Legge di Conversione 31 Luglio. 2017, n. 119. Available online: http://www.trovanorme.salute.gov.it/norme/dettaglioAtto?id=60201 (accessed on 23 January 2020).

38. Rodriguez, A.M.; Do, T.Q.N.; Goodman, M.; Schmeler, K.M.; Kaul, S.; Kuo, Y.F. Human papillomavirus vaccine interventions in the U.S.: A systematic review and metaanalysis. Am. J. Prev. Med. 2019, 56, 591-602. [CrossRef] [PubMed]

39. Berenson, A.B.; Hirth, J.M.; Fuchs, E.L.; Chang, M.; Rupp, R.E. An educational intervention to improve attitudes regarding HPV vaccination and comfort with counseling among US medical students. Hum. Vaccine Immunother. 2019, 6, 1-6. [CrossRef]

(C) 2020 by the authors. Licensee MDPI, Basel, Switzerland. This article is an open access article distributed under the terms and conditions of the Creative Commons Attribution (CC BY) license (http://creativecommons.org/licenses/by/4.0/). 